\title{
Tobacco Use among Females in an Urban Community of Imphal West, Manipur
}

\author{
Laishram Jenibala Devi ${ }^{1}$, Dr Jalina Laishram ${ }^{2}$, Laishram Jayarani ${ }^{3}$, Dr Ngangom \\ Meeta Devi ${ }^{4}$, Dr Dilip Ingudum ${ }^{5}$ \\ ${ }^{I}$ Department of Sociology, CMJ University, Shillong, Meghalaya, India \\ ${ }^{2}$ Department of Community Medicine, Regional Institute of Medical Sciences, Imphal, Manipur, India \\ ${ }^{3}$ Department of Extension Education, Central Agricultural University, Iroisemba, Imphal, Manipur, India \\ ${ }^{4}$ Department of History, G.P Women's College, Imphal, Manipur, India \\ ${ }^{5}$ Medical Officer, Manipur Health Services, Lamphelpat, Imphal, Manipur, India
}

\begin{abstract}
Background: Tobacco use is a growing global public health problem. The adverse effects of tobacco use on health are well known. The objectives of this study was to determine the prevalence of tobacco use and to determine the association of tobacco use with selected variables like age, education, occupation, etc among females in an urban community.
\end{abstract}

Methods: A cross sectional study using personal interviews was carried out on 307 individuals aged 18 years and above. Descriptive statistics and Chi-square test was used for analysis.

Results: The prevalence of ever use of tobacco use was $58.6 \%$ and of which $97.2 \%$ were current users. Tobacco was used predominantly in smokeless form (zarda pan, khaini, gutkha) by $85.6 \%$ of the users. Only smoked tobacco was used by $4.4 \%$ of the users. The commonest influencing factor for tobacco use was peer pressure.

Conclusion: Prevalence of tobacco use in this community was high. There is a need to develop effective health education and multifactorial tobacco quitting strategies with focus on help and support for those who wish to quit tobacco.

Key words: Cross sectional study, females, urban community, Manipur, tobacco use.

\section{Introduction}

Tobacco consumption is a global public health problem. Approximately one person dies every six seconds due to tobacco and this accounts for one in 10 adult deaths. Up to half of current users will eventually die of a tobacco-related disease. It kills nearly six million people a year of whom more than 5 million are users and ex users and more than 600000 are non-smokers exposed to second-hand smoke. The burden of tobaccorelated illness and death is heaviest in low- and middle-income countries. India has the second largest number of smokers in the world, after China [1].

According to GATS- India (2009-10), the prevalence of overall tobacco use among males is $48 \%$ and that among females is $20 \%$ [2].

Smoking tobacco among women in most high income countries has increased over the last two decades. The estimated number of women smokers worldwide is about 200 million and if the current trend persists it will be about 500 million within the next two decades. The biggest rise in female smoking is projected to be in the less developed countries $[3,4,5]$.

Prevalence of tobacco use among women is increasing. There is a huge problem of widespread smokeless tobacco use among Indian women, particularly among the disadvantaged women. Rani et al reported that $2.4 \%$ of Indian women smoke and $12 \%$ chew tobacco [6].

Problem of tobacco use in India is complex and it is characterized by wide availability of low priced smoking and smokeless tobacco products. Apart from smoking and chewing, tobacco is used in inhaled, nasal and teeth and gums application forms [7].

Owing to variety of tobacco products consumed in India, varying health consequences are encountered . It is responsible for half of all the cancers in men and a quarter of all cancers in women, [8]in addition to being a risk factor for cardiovascular diseases and chronic obstructive pulmonary diseases.[9,10] India also has one of the highest rates of oral cancer in the world and it has been partly attributed to high prevalence of tobacco chewing $[11,12]$.

The prevalence of smoking among women is low in most areas due to social unacceptability, but is somewhat common in parts of north, east, northeast India and Andhra Pradesh [3]. Other studies have estimated the prevalence of tobacco use among women to be $17 \%$ to $45 \%$ [13]. 
Females form a vulnerable group due to various factors like illiteracy, poverty, malnutrition, child bearing and social inequality [14].The magnitude of the health problems of tobacco use can be increased manifold coupled with the above mentioned factors. There is paucity of data related to tobacco use among women in the north-eastern states of India including Manipur. Hence, this study was conducted with the objectives to determine the prevalence of tobacco use among women and to determine the association with selected variables of interest like age, education, occupation, income, marital status, religion, knowledge of harmful effects of tobacco and presence of another tobacco user in the family.

\section{Materials and Methods}

This cross sectional study was conducted in an urban community of Imphal, Manipur. Manipur is in the north eastern part of India. Manipur also shares its border with Myanmar. The study population comprises of all women aged 18 years and above residing in this urban community. A sample size of 307 was calculated using a prevalence of $20 \%$ for females from GATS-India (2009-10), 95\% confidence interval and assuming a non response rate of $20 \%$. Sampling was done using simple random sampling method. The sampling frame was prepared from the most recent electoral roll. Data was collected by interview using a predesigned pretested structured questionnaire. The questionnaire had questions on socio demographic characteristics, form of tobacco used, frequency, duration of tobacco use and reasons for initiating tobacco use. It also included questions on harmful effects of use and presence of another tobacco user in the family.

Ever user was defined as those who had used any tobacco product in her lifetime, even once. Ever users are again classified as current user and past user. Current users are those who have used any tobacco product anytime in the last 30 days. Past users are those who had used any tobacco product any time but not within the last 30 days. Never users are those who have never used any form of tobacco.

The various tobacco products mentioned in the study were divided into smoked forms and smokeless forms. Cigarette and bidi are examples of smoked form of tobacco. Bidi is hand made by rolling in tendu leaf with dried tobacco leaf and with string. It is filterless. Smokeless tobacco is tobacco that is not burned. It can be chewed, dipped, inhaled or applied to teeth and gums. They are khaini, zarda pan, pan masala or gutkha to name some. Khaini typically consists of tobacco mixed with slaked lime and additional flavorings. It is kept in the mouth between the cheeks and gums. The product is available both in loose form and in individual portioned sachets. In Zarda pan the main ingredients are the betel leaf, areca nut (supari), slaked lime (chuna), and catechu (katha) and flakes of dried tobacco called as zarda. Paan masala or gutkha contains areca nut, slaked lime, catechu, and condiments, with powdered tobacco. It comes in sachets and tins, which are easy to carry and store. Tobacco leaf in dried form is also taken along with betel leaf and quid, with or without lime.

Regarding the level of knowledge of the harmful effects of tobacco, those who could give atleast one correct response were considered to have "some knowledge" and those who could not name even one correct harmful effect were considered to have "no knowledge."

Descriptive statistics like mean, percentages and proportions were used. Chi- square test was used to see the association between tobacco use and selected variables like age, educational status, occupation, income, religion, knowledge of harmful effects of tobacco and presence of another tobacco user in the family. A p-value of $<0.05$ was taken as significant. Informed consent was taken from all the respondents and confidentiality was maintained. Approval for the study was granted by Institutional Review Board of CMJ University, Shillong, Meghalaya, India.

\section{Results}

A total of 307 women participated in the study. Mean age of the respondents was $34.4( \pm 13.3)$ years. Table 1 shows the socio-demographic characteristics of the respondents. More than half of the respondents were in the age group of 20-39 years $(\mathrm{n}=169,55.3 \%)$. Majority of the respondents were Hindu by religion $(78.2 \%)$. Literacy rate was $89 \%$ with over half having more than ten years of schooling. Housewives comprised more than half $(55.7 \%)$ and $28.3 \%$ were employed. Forty nine women $(16 \%)$ were students. Majority of the respondents were married $(\mathrm{n}=235,76.5 \%)$. Majority had a monthly family income between Rs 5000 to Rs 10000

The prevalence of ever use of tobacco in this study was found to be $58.6 \%(\mathrm{n}=180)$. Among the ever users, $97.2 \%(n=175)$ were current users and $2.8 \%(n=5)$ were past users. Of the ever users, $143(79.4 \%)$ were daily users (Table 2).

Smokeless tobacco was more commonly used as compared to smoked form. Only smokeless form of tobacco was used by $85.6 \%(n=154)$ of the users. Eight respondents (4.4\%) used only smoked form of tobacco while $10 \%(\mathrm{n}=18)$ used both smokeless and smoked tobacco (Table 3). Most common form of smokeless tobacco used was zarda pan $(n=147,59.5 \%)$ followed by gutkha or pan masala $(n=36,14.6 \%)$, tobacco leaf with $\operatorname{pan}(\mathrm{n}=33,13.4 \%)$ and khaini $(\mathrm{n}=3,1.2 \%)$. Cigarette and bidi was smoked by $7.3 \%$ and $4 \%$ of the respondents respectively (Table 4). Mean age of first use was found to be $25.5( \pm 10)$ years. Most of the respondents 
$(\mathrm{n}=78,43.3 \%)$ started using tobacco in the age group of 20-29 years and one-fourth started using within 10-19 years of age $(n=46)$. Of the total respondents, $242(78.8 \%)$ had some knowledge of harmful effects of tobacco and majority of them knew that it causes cancer. Peer pressure was named as the most common influencing factor for tobacco use by $90(43.3 \%)$ respondents. Other reasons reported were experimentation $(n=48,23.1 \%)$, imitation of others $(n=43,20.7 \%)$, for medicinal purpose to relieve nausea, pain and stress $(n=11,5.3 \%)$. Another $13(6.2 \%)$ respondents said that there was no influencing factor in their initiation of tobacco use.

The association between tobacco use and respondents' characteristics is shown in Table 5. The prevalence of tobacco use was highest among the age group of 50-59 years as compared to other age groups and this was statistically significant $(\mathrm{p}=0.000)$. Tobacco use was more prevalent among those who were illiterate and this was found to be statistically significant $(73.5 \%, \mathrm{p}=0.000)$. Tobacco use was more prevalent among the self employed women as compared to women in other occupation and this was statistically significant $(\mathrm{p}=0.000)$. Majority of the ever users were married and this was statistically significant $(\mathrm{p}=0.000)$. Ever users of tobacco were more likely to have another tobacco user in the family and this was statistically significant $(\mathrm{p}=0.000)$. Religion, family income and knowledge of harmful effects of tobacco were not statistically associated with tobacco use.

Television and radio $(n=261,70.4 \%)$ were the most common source of information about the harmful effects of tobacco followed by warning on tobacco product packets $(n=30,8.1 \%)$ and personal experience $(n=26,7 \%)$. Of the current users $149(82.7 \%)$ were willing to quit tobacco and $138(76.7 \%)$ have tried quitting.

\section{Discussion}

The prevalence of ever use of tobacco among women in our study was found to be $58.6 \%$ and that of current user was $97.2 \%$ which is higher than that reported from other parts of the country $[2,6,15]$ and elsewhere [17].The proportion of past users in our study was $2.4 \%$ which is consistent with that reported by Daniel et al, 2008 [16] and slightly lower than the 4.3\% reported by Joshi et al, 2010 [18] and Fakhfakh et al, 2002 [17].

In this study, smokeless tobacco was more commonly used as compared to smoked form. Zarda pan, gutkha or pan masala were the most commonly used form of tobacco in this study and similar findings were also reported [15,16,21]. Single form of tobacco use (either smoking only or smokeless only) were found in $90 \%$ while use of both smoked and smokeless was found in $10 \%$ of the women. Another study reported a $40 \%$ of single form use of tobacco [15].

The mean age of first use was 25.5 years which was comparable with other studies [17,18]. The higher age of initiation of tobacco use can be used for effective health education. Such an approach will be feasible in the study area as this one is a highly literate community. Of the current users $82.7 \%$ were willing to quit tobacco use which is much higher than reported in other studies [18]. Knowledge of harmful effects of tobacco in the study population was found to be comparable with a study in India [18] but this level was lower than that reported in a study elsewhere [17].

Educational was significantly associated with tobacco use and the prevalence was highest among those women who were illiterate. This is consistent with observations that those with lower level of education are more likely to use tobacco $[6,17,18,19]$. In this study, the age wise prevalence of tobacco use was higher as the age advanced and the highest rate was found in the age group of 50-59 years and then declined after 60 years. Similar finding was also reported by other workers $[6,18]$ but another study reported two peaks between $30-40$ years and after 50 years [15].

Those who were married had a higher rate of tobacco use as compared to the unmarried respondents. This may be due to influences of the spouses consuming tobacco. Similar association between tobacco use and marital status was also reported. [20].Peer pressure was named as the most common reason for initiation of tobacco use and similar findings were also reported in other studies [16].

\section{Conclusion}

The findings of the study show that tobacco use is becoming a huge problem among the females. There is a need to increase the awareness of the people on all the harmful effects of tobacco use. The cross-sectional nature of our study and self reported rates of tobacco use are the major limitations of our study. Since this study was conducted in an urban population, the findings might not be generalized to the entire state of Manipur. Another study with larger sample size is recommended eliciting more information on different types of tobacco and enabling factors of this unhealthy habit.

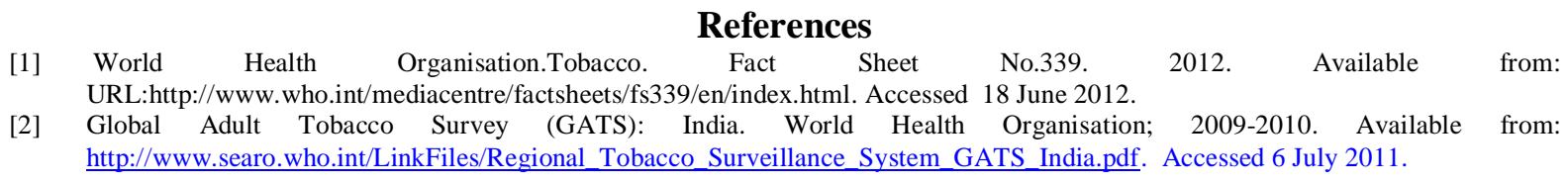


[3] Reddy KS, Gupta PC, editors. Report on tobacco control in India. Ministry of Health and Family Welfare, Government of India, New Delhi, India 2004;57-61.

[4] Jha P, Chaloupka F, editors. Tobacco control in developing countries (Oxford:Oxford University Press;2000).

[5] World Health Organisation (WHO). Tobacco or health: A global status report, Geneva:WHO;1997.

[6] Rani M, Bonu S, Jha P, Nguyen SN, Jamjourm L. Tobacco use in India: Prevalence and predictors of smoking and chewing in a national cross sectional household survey. Tob Control, 12,2003,341. Available from: URL: http://www.tobaccocontrol.com/cgi/content/full/12/4/e4. Accessed 28 June, 2011.

[7] Jhanjee S. Tobacco control in India-Where are we now? Delhi Psychiatry Journal, 14(1),201126-32.

[8] World Health Organisation. Tobacco control:strengthening national efforts, World Health Report; WHO , Geneva, Switzerland.2003;91-5.

[9] Gupta R, Prakash H, Gupta VP. Prevalence and determinants of coronary heart disease in a rural population in India. J Clinl Epidemiol, 50,1997,203-9.

[10] Padmavati S. Prevention of heart disease in India in the $21^{\text {st }}$ century. Need for a concerted effort. Indian Heart J, 54, 2002, 99-102

[11] Franceschi S, Bidoli E, Herroro R, Munoz N. Comparison of cancers of the oral cavity and pharynx worldwide: etiological clues. Oral Oncology, 36, 2000,106-15.

[12] Dikshit R, Kanhere S. Tobacco habits and risk of lung, oropharyngeal and oral cancer: a population based case-control study in Bhopal, India. Int J Epidemiol, 29, 2000, 609-14.

[13] Pratinidhi A, Gandham S, Shrotri A, Patel A, Pardeshi S. Use of 'Mishri': A smokeless form of tobacco during pregnancy and its perinatal outcome. Indian J Community Med, 2010, 35,2010, 14-8.

[14] Centers for Disease Control and Prevention(CDC). http://www.cdc.gov/tobacco/global/gyts/factsheets/searo/2006/India_factsheet.htm. Accessed 23 January, 2011.

[15] Srivastava M, Parakh P, Srivastava M. Predictors and prevalence of nicotine use in females: A village-based community study. Industrial Psychiatry J, 19(2), 2010, 125-9.

[16] Daniel AB, Nagaraj K, Kamath R. Prevalence and determinants of tobacco use in a highly literate rural community in south India. Natl Med J India, 21, 2008, 163-5.

[17] Fakhfakh R, Hsairi M, Maalej M, Achour N, Nacef T. Tobacco use in Tunisia: behavior and awareness. Bull World Health Organ, $80,2002,350-56$.

[18] Joshi U, Modi B, Yadav S. A study on prevalence of chewing form of tobacco and existing quitting patterns in urban population in Jamnagar, Gujarat. Indian J Community Med, 35, 2010, 105-8.

[19] Gupta R. Smoking, educational status and healthy equity in India. Indian J Med Res, 124, 2006, 15-22.

[20] Manimunda SP, Benegal V, Sugunan AP, Jeemon P, Balakrishna N, Thennarusu K, Pandian D, Pesala KS. Tobacco use and nicotine dependency in a cross-sectional representative sample of 18,018 individuals in Andaman and Nicobar Islands, India. BMC Public Health, 12, 2012, 515. Available from: http://www.biomedcentral.com/1471-2458/12/515. Accessed 23 January 2013.

[21] Croucher R, Islam S, Jarvis M, Garett M, Rahman R, Shajahan S, Howells G. Toabacco dependence in a UK Bangladeshi female population: a cross-sectional study. Nicotine Tob Res, 4(2),2002, 171-6.

Table 1. Socio-demographic characteristics of the respondents $(n=307)$

\begin{tabular}{|c|c|c|}
\hline Characteristics & Number & $\%$ \\
\hline $\begin{aligned} \operatorname{Age} \operatorname{group}(\mathrm{yrs}) \mathbf{x}_{\leq 19} & \end{aligned}$ & 38 & 12.4 \\
\hline $20-29$ & 85 & 27.8 \\
\hline 30-39 & 84 & 27.5 \\
\hline $40-49$ & 51 & 16.6 \\
\hline $50-59$ & 32 & $\mathbf{1 0 . 5}$ \\
\hline$\geq 60$ & 17 & 5.6 \\
\hline $\begin{array}{l}\text { Educational Status: } \\
\text { Illiterate }\end{array}$ & 34 & 11.1 \\
\hline$<$ ClassX & 115 & 37.5 \\
\hline ClassX-XII & 104 & 33.9 \\
\hline$\geq$ Graduate & 54 & $\mathbf{1 7 . 6}$ \\
\hline \multicolumn{3}{|l|}{ Occupation: } \\
\hline Unemployed/Housewife & 171 & 55.7 \\
\hline Govt. employed & 13 & 4.2 \\
\hline Private sector employed & 14 & 4.6 \\
\hline Self employed & 60 & 19.5 \\
\hline Student & 49 & 16 \\
\hline \multicolumn{3}{|l|}{ Marital status: } \\
\hline Married & 235 & 76.5 \\
\hline Unmarried & 72 & 23.5 \\
\hline $\begin{array}{l}\text { Religion: } \\
\text { Hindu } \\
\end{array}$ & 240 & 78.2 \\
\hline Non- Hindu & 67 & 21.8 \\
\hline $\begin{array}{c}\text { Family income/month(Rs): } \\
<5000\end{array}$ & 54 & 17.6 \\
\hline $5000-9999$ & 123 & 40.1 \\
\hline $10000-14999$ & 51 & 16.6 \\
\hline$\geq 15000$ & 79 & 25.7 \\
\hline
\end{tabular}


Table 2. Prevalence of tobacco use $(n=307)$

\begin{tabular}{|c|c|c|}
\hline Tobacco use & Number & Prevalence(\%) \\
\hline Never user & 127 & 41.4 \\
\hline Ever user & 180 & 58.6 \\
\hline Current user & 175 & 97.2 \\
\hline Past user & 5 & 2.8 \\
\hline
\end{tabular}

Table 3. Form of tobacco use

\begin{tabular}{|l|c|}
\hline Form of tobacco & $\mathbf{N}(\%)$ \\
\hline Smoking only & $\mathbf{8 ( 4 . 4 )}$ \\
\hline Smokeless only & $154(85.6)$ \\
\hline Both smoking \& smokeless & $18(10)$ \\
\hline Total & $180(100)$ \\
\hline
\end{tabular}

Table 4. Distribution of respondents by types of tobacco products used *

\begin{tabular}{|l|c|}
\hline Tobacco product & $\mathrm{N}(\%)$ \\
\hline Zarda pan & $147(59.5)$ \\
\hline Gutkha & $36(14.6)$ \\
\hline Tobacco leaf with pan & $33(13.4)$ \\
\hline Cigarette & $18(7.3)$ \\
\hline Bidi & $10(4)$ \\
\hline Khaini & $3(1.2)$ \\
\hline Total & $247(100)$ \\
\hline
\end{tabular}

*Multiple answers

Table 5. Association between tobacco ever use and respondents' characteristics $(n=403)$

\begin{tabular}{|c|c|c|c|}
\hline \multirow[t]{2}{*}{ Characteristics } & \multicolumn{2}{|c|}{ Ever user, n(\%) } & \multirow[t]{2}{*}{ p-value } \\
\hline & Yes & No & \\
\hline \multicolumn{3}{|l|}{ Age group(yrs): } & \multirow{7}{*}{0.000} \\
\hline$\leq 19$ & $9(23.7)$ & 29(76.3) & \\
\hline 20-29 & $47(55.3)$ & $38(44.7)$ & \\
\hline 30-39 & $58(69)$ & $26(31)$ & \\
\hline $40-49$ & $34(66.7)$ & 17(33.7) & \\
\hline $50-59$ & 23(71.9) & $9(28.1)$ & \\
\hline$\geq 60$ & 9(52.9) & $8(47.1)$ & \\
\hline Educational Status: & \multirow[b]{2}{*}{$25(73.5)$} & \multirow[b]{2}{*}{$9(26.5)$} & \multirow{5}{*}{0.000} \\
\hline Illiterate & & & \\
\hline$<$ ClassX & 82(71.3) & $33(28.7)$ & \\
\hline ClassX-XII & $45(43.3)$ & $59(56.7)$ & \\
\hline$\geq$ Graduate & $28(51.9)$ & $26(48.1)$ & \\
\hline Occupation: & \multirow{2}{*}{$112(65.5)$} & \multirow[b]{2}{*}{$59(34.5)$} & \multirow{6}{*}{0.000} \\
\hline Unemployed/Housewife & & & \\
\hline Govt. employed & $9(69.2)$ & $4(30.8)$ & \\
\hline Private sector employed & $7(50)$ & $7(50)$ & \\
\hline Self employed & 44(73.3) & $16(26.7)$ & \\
\hline Student & $8(16.3)$ & 41(83.7) & \\
\hline Marital status: & & & \multirow{3}{*}{0.000} \\
\hline Married & $157(67.1)$ & 78(32.9) & \\
\hline Unmarried & $23(31.9)$ & $49(68.1)$ & \\
\hline Religion: & \multirow[b]{2}{*}{$143(59.6)$} & \multirow[b]{2}{*}{ 97(40.4) } & \multirow{3}{*}{0.794} \\
\hline Hindu & & & \\
\hline Non- Hindu & $37(55.2)$ & $30(44.8)$ & \\
\hline Family income/month(Rs): & \multirow[b]{2}{*}{ 31(57.4) } & \multirow[b]{2}{*}{$23(42.6)$} & \multirow{5}{*}{0.466} \\
\hline$<5000$ & & & \\
\hline $5000-9999$ & 69(56.1) & $54(43.9)$ & \\
\hline 10000-14999 & $35(68.6)$ & $16(31.4)$ & \\
\hline$\geq 15000$ & $45(57)$ & 34(43) & \\
\hline \multicolumn{3}{|c|}{ Knowledge of harmful effects of tobacco: } & \multirow{3}{*}{0.97} \\
\hline Some knowledge & $142(58.7)$ & $100(41.3)$ & \\
\hline No knowledge & $38(58.5)$ & $27(41.5)$ & \\
\hline \multicolumn{3}{|c|}{ Presence of another user in the family: } & \multirow{3}{*}{0.000} \\
\hline Yes & 85(71.4) & $34(28.6)$ & \\
\hline No & 95(50.8) & 92(49.2) & \\
\hline
\end{tabular}

